\title{
Papular acrodermatitis of childhood
}

\section{An Australia antigen disease}

\author{
FERDINANDO GIANOTTI \\ From the Department of Dermatology, University of Milan, Italy
}

\begin{abstract}
Gianotti, F. (1973). Archives of Disease in Childhood, 48, 794. Papular acrodermatitis of childhood: an Australia antigen disease. Papular acrodermatitis (PAC) is a fairly widespread, probably slightly infectious, nonrelapsing disease of childhood characterized by (a) papular eruption on the face and limbs lasting 20 days or more, (b) reactive reticulohistiocytic lymphadenitis, and (c) acute hepatitis, usually anicteric, which commonly lasts about 2 months.

Australia antigen is always present; it is detectable 10 or more days after the onset of the skin eruption and persists from 2 months to several years.

The mother of some children with PAC are found to be carriers of Au antigen, as are some sibs when tested many years later. Whether the causative agent of PAC is the same as that causing serum hepatitis, or is different, remains to be established.
\end{abstract}

Papular acrodermatitis of childhood (PAC) is an infective disease characterized by a recognizable skin eruption localized to the face and limbs, by enlargement of lymph nodes (mainly inguinal and axillary), and by an acute hepatitis which is usually anicteric, but is always associated with Australia antigenaemia. The present article reviews current knowledge of the condition and its possible relation to serum hepatitis.

PAC was first recognized in Milan in 1953 and described by Gianotti (1955). Since then the disease has been reported all over the world (Bernhardt and Szczepanski, 1968; Blagoslovenskii, 1970; Blancher et al., 1962; Boyanov, Boyanov, and Dimitrova, 1963; Braun-Falco and Rupec, 1964; Brown and Rentiers, 1969; Despres et al., 1969; Duperrat and Puissant, 1958; Eiloart, 1966; Jeune, Moulin, and Rosenberg, 1964; Nurse, 1967; Pomposiello and Abulafia, 1968; Reich, 1963; Schirren and Mütter, 1964; Stevanovic and Sofronic, 1962; Terao and Takemura, 1971; Thiers and Moulin, 1964; Vulcan, Wolkonsky, and Nicolescu, 1965; Winkelmann and Bourlond, 1965; Woerderman, 1965).

\section{Clinical and pathological features}

Cutaneous lesions. The eruption consists of monomorphic, lenticular, flat erythematopapular, nonitching lesions, symmetrically spread over face, buttocks, and limbs (Fig. 1). The trunk is usually spared, but a transient rash may be seen on it in the early eruptive phase; the eruption develops in a few days and lasts for 15 to 20 days or more. The mucous membranes are not affected. This is the eruption usually found in children between 2 and 6 years of age; but in infancy larger lesions 5 to $10 \mathrm{~mm}$ in diameter are seen, while in older children the dermatitis is often micropapular, 1 to $2 \mathrm{~mm}$ in diameter. In the few cases observed in adults the lesions had the typical lenticular form. Occasionally the lesions have a purpura-like appearance or are infiltrated so as to protrude from the skin surface. During the eruptive phase the Koebner reaction may be used. The skin eruption does not relapse. Histo-
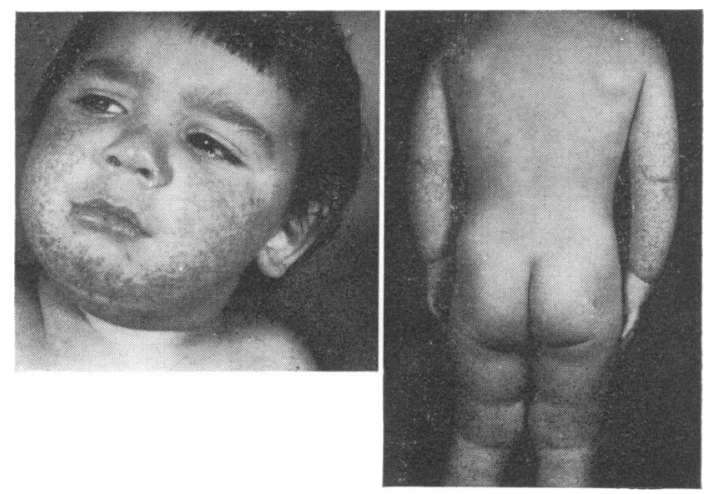

(a)

(b)

FIG. 1.-Typical case of papular acrodermatitis. The cutaneous eruption remains localized to the (a) face and (b) limbs. 
logically, the cutaneous lesion shows a perivascular lympho-monocytic and histiocytic infiltration of the papillary and superficial dermis. In the epidermis Langerhans cells are abundant, as shown by electron microscopy.

Lymphadenitis. The enlargement of lymph nodes, mainly inguinal and axillary, lasts for 2 or 3 months. Biopsy studies show a 'reactive reticulohistiocytic hyperplasia' consisting of (a) conspicuous activation of the endothelial components, with thickening of the endothelium of the capillaries and prominent sinuses, (b) proliferation of pleomorphic reticulohistiocytic elements in small groups, within and outside the follicle centres, sometimes with the presence of binucleate cells. With the electron microscope (Jean, Lambertenghi, and Gianotti, 1968) the main proliferating histiocytes appear to be sinusoid-lining cells, sometimes containing Langerhans granules.

Hepatitis. Acute hepatitis always occurs; it is generally anicteric but in some children, usually those over 6 years, jaundice may appear about 20 days after the onset of the skin eruption (Gianotti, 1966; Jean et al., 1967; Bologa, 1966; Cieri, Rezza, and Anibaldi, 1966; De Benedetti, 1969; Ricciardiello, 1969). The liver usually remains clinically enlarged, but not tender, for 1 to 3 months. There are high levels of SGOT and SGPT (sometimes exceeding 2000 units $/ \mathrm{ml}$ ), aldolase, glucose-6-phosphatase, and alkaline phosphatase; bromsulphalein retention is raised (up to $40 \%$ ), but serum bilirubin is usually not increased. In most cases the hepatitis begins at the same time as, or a week or two after, the skin eruption. After the first month when the eruption is fading the hepatitis is generally in a fully developed stage.

The changes in serum enzymes usually persist for 2 to 3 months but levels sometimes remain raised for months or even years. Liver biopsy (in 32 children) has shown that during the dermatitis phase the histological picture is indistinguishable from that of acute viral hepatitis (Jean et al., 1967). 6 months to a year or more after the onset of the dermatitis liver biopsy has shown either a normal histological picture, or that of a persistent chronic hepatitis. Rarely the picture has been that of a chronic aggressive hepatitis with moderate activity, type $A$ (De Groote et al., 1968) and, in these cases, SGOT and SGPT levels often remain slightly increased. The liver eventually returns to normal, though this may take as long as 4 years. 23 biopsies obtained from 16 children at different phases of the anicteric hepatitis have been studied by electron microscopy, with findings similar to those found in acute viral hepatitis (Jean et al., 1967).

Other symptoms and laboratory findings. Constitutional symptoms at no stage are more than slight, with mild fever and lassitude. The blood shows normal erythrocyte sedimentation rate (ESR), mild hypochromic anaemia, increased vascular fragility with normal platelets; prothrombin activity 50 to $90 \%$; leucocytes normal or diminished with a relative abundance of monocytic cells (up to $20 \%$ ) and Turk's cells. The electron microscope shows these monocytes to be identical with those found in infectious mononucleosis (Jean, Ranzi, and Lambertenghi, 1969). In bone marrow there is an increase in the number of histiocytes and eosinophils. The Paul-Bunnell test, the dye test, and complement-fixation for toxoplasmosis are negative. In the acute phase there is an increase in $a_{2}$ - and $\beta$-globulins; in the late phase $\gamma$-globulins may be increased.

\section{Epidemiology}

The infectiousness of the disease appears low, so that more than one case occurs only occasionally in infant communities or in a family. Sporadic cases occur throughout the year, and though there is no marked seasonal incidence, PAC frequently occurs within a period of a few days in some children in distant districts of a city, though it is not known what these children might have in common. The children have not received injections or blood transfusion. Occasionally, the disease occurs in sibs after 1 or more years; in these families the patient who had originally suffered from PAC has remained an $\mathrm{Au}$ antigen carrier. Children with Down's syndrome seem to be predisposed to PAC, and we have seen 5 such cases.

\section{Aetiological findings}

PAC shows all the characteristic features of a diffuse hyperplasic reactive reticulohistiocytosis of viral orgin, though the virus is still unidentified despite many investigations by us and others.

Electron microscopy findings. In lymph nodes of children with PAC, particles 40 to $50 \mathrm{~nm}$ in diameter, bounded by a membrane and containing an electron-opaque core, have been observed within the cytoplasm of some sinusoid-lining cells (Jean $e t$ al., 1968). These particles have a similar structure to those seen in organ cultures inoculated with serum from hepatitis patients with Au antigenaemia (Jenson et al., 1970), and to those seen in the endoplasmic reticulum of hepatocytes of $\mathrm{Au}$ antigen carriers (Stein, Fainaru, and Stein, 1972). These particles resemble the virus-like particles about $\mathbf{4 2}$ $\mathrm{nm}$ in diameter that have been found in $\mathrm{Au}$ antigen positive hepatitis patients by Dane, Cameron, and Briggs (1970). Also, in the cytoplasm of some macrophages and reticular cells of the liver we have found (Jean et al., 1967) some spherical particles, showing an electron-opaque core, surrounded by a double membrane with an outer granular layer (Fig. 2 ); these particles appear to be in close connexion with cisternae of the endoplasmic reticulum and Golgi's apparatus. Indeed, such virus-like particles 


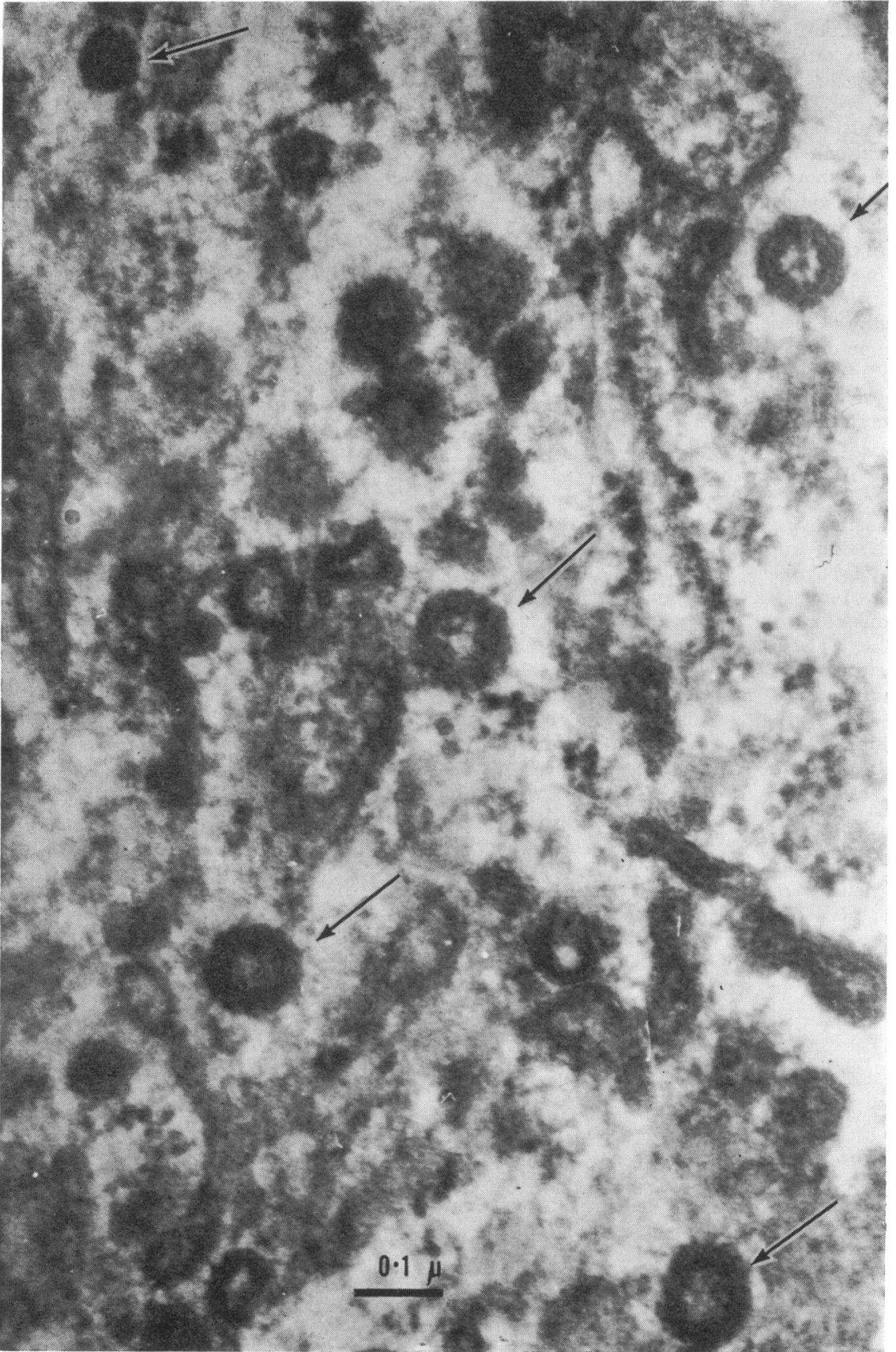

FIG. 2.-Liver biopsy during the dermatitis phase. Reticulohistiocytic cell in the cytoplasm containing numerous particles (arrows) with electron-opague core, surrounded by double membrane with an outer granular layer. 
show the same structures as those seen in the cytoplasm of hepatocytes and Kupffer's cells of children suffering from infectious icteric hepatitis, after azothioprine administration (Sirtori, 1970).

Australia antigen (AuAg). We have assayed Australia antigen in the serum of 39 children with PAC by immunodiffusion as described by Prince (1968), or by electro-syneresis, as described by Bedarida, Trinchieri, and Carbonara (1969). AuAg was repeatedly detected in the serum of all 39 children throughout the skin eruptive phase (Gianotti, 1970, 1971). In 4 children AuAg appeared 10 to 15 days after the onset of the eruption, while in the other 35 children AuAg was already present when they came under observation.

Other investigators (De Gaspari, Bardare, and Costantino, 1970; Piñol-Aguade and Mascaro, 1971) have detected AuAg in PAC, whereas the Milan antigen, i.e. the serum antigen associated with infectious epidemic hepatitis, is absent (Costantino et al., 1973).

Table I gives the results of following 25 children

\section{TABLE I}

Persistence of Australia antigen in the blood of 25 children after papular acrodermatitis

\begin{tabular}{c|c|c|c}
\hline AuAg still positive & \multicolumn{2}{|c}{ AuAg negative } \\
\cline { 1 - 3 } No. cases & $\begin{array}{c}\text { Length of time } \\
\text { since skin } \\
\text { eruptions }(\mathrm{yr})\end{array}$ & No. cases & $\begin{array}{c}\text { Length of time } \\
\text { after skin } \\
\text { eruption }\end{array}$ \\
\hline 4 & $4 \mathrm{mth}$ & 7 & Within 2 mth \\
3 & 1 & 3 & Within 3 mth \\
2 & 2 & & \\
2 & 6 & & \\
2 & 8 & & \\
1 & 11 &
\end{tabular}

with PAC. 10 of the 25 became AuAg negative within the first 3 months, while 15 so far remain positive, either having remained positive throughout or having shown short intervals of being negative. Of 3 sisters who all suffered from PAC 8 years ago, only one still remains AuAg positive.

AuAg becomes detectable in the serum by the time the hepatitis has developed and SGOT and SGPT have reached high levels. The persistence of $\mathrm{AuAg}$ in the blood during subsequent months is usually accompanied by slightly raised levels of SGOT and SGPT. 1 to 2 years after the eruption, AuAg may still be present with normal SGOT and SGPT levels.

A search for AuAg among other members of the family of children with PAC revealed that 3 mothers of children in the eruptive phase were AuAg positive. 3 mothers whose children had been affected by PAC 11, 6, and $1 \frac{1}{2}$ years before were also found to be AuAg positive. 2 children whose brothers had suffered from PAC, 6 and 1 years before, were AuAg positive. In these families the child who had originally been affected by PAC usually remained AuAg positive.

\section{Differential diagnosis}

PAC has characteristic clinical features so that most cases are easily recognized. However, there are some papular eruptions of childhood from which it has to be differentiated. New papular erythema of childhood (Brunner, Rubin, and Dunlap, 1962) is characterized by small conical erythematous papules, sometimes coalescent, generally sited unilaterally near the axilla, on an arm or side of the trunk; itching is moderate. Frictional lichenoid eruption in children (Waisman and Sutton, 1966) presents as pale, flat papules, 1 to $2 \mathrm{~mm}$ in diameter, closely aggregated centrally in the plaque; these papules are mainly localized on the elbow, knee, dorsum of fingers, and the extensor aspects of the forearms; itching is absent. The cutaneous eruption papulovesicular-acrolocated syndrome described by us (Crosti and Gianotti, 1964), and then by others (Brown and Rentiers, 1969; Eiloart, 1966; Hjorth, Kopp, and Osmundsen, 1967; Puissant et al., 1966; Stevanovic and Sofronic, 1962; Terao and Takemura, 1971; Winkelmann and Bourlond, 1965), is more likely to cause confusion, the most important features of the two diseases being summarized in Table II.

\section{Comment}

The nature of the hepatitis that occurs in this disease remains to be established. The hepatitis of PAC is distinguishable from that caused by yellow fever, by cytomegalovirus infection, and by EpsteinBarr virus infection (giving rise to infectious mononucleosis), since the hepatitis of these diseases has distinct clinical and pathological features, and since it is never associated with $\mathrm{Au}$ antigenaemia. Short-incubation infectious hepatitis (virus A), though indistinguishable from PAC in its histopathological aspects, can be differentiated both on clinical grounds and from the lack of Au antigenaemia.

It is more difficult to establish the relation, if any, between long-incubation hepatitis (virus $B$ ) and the hepatitis of PAC, now that it is clear that Au antigenaemia is not peculiar to serum hepatitis but occurs also in PAC. Some of the features of PACthe constant association of hepatitis with skin 
TABLE II

Differentiation of papular acrodermatitis from papulo-vesicular-acrolocated syndrome

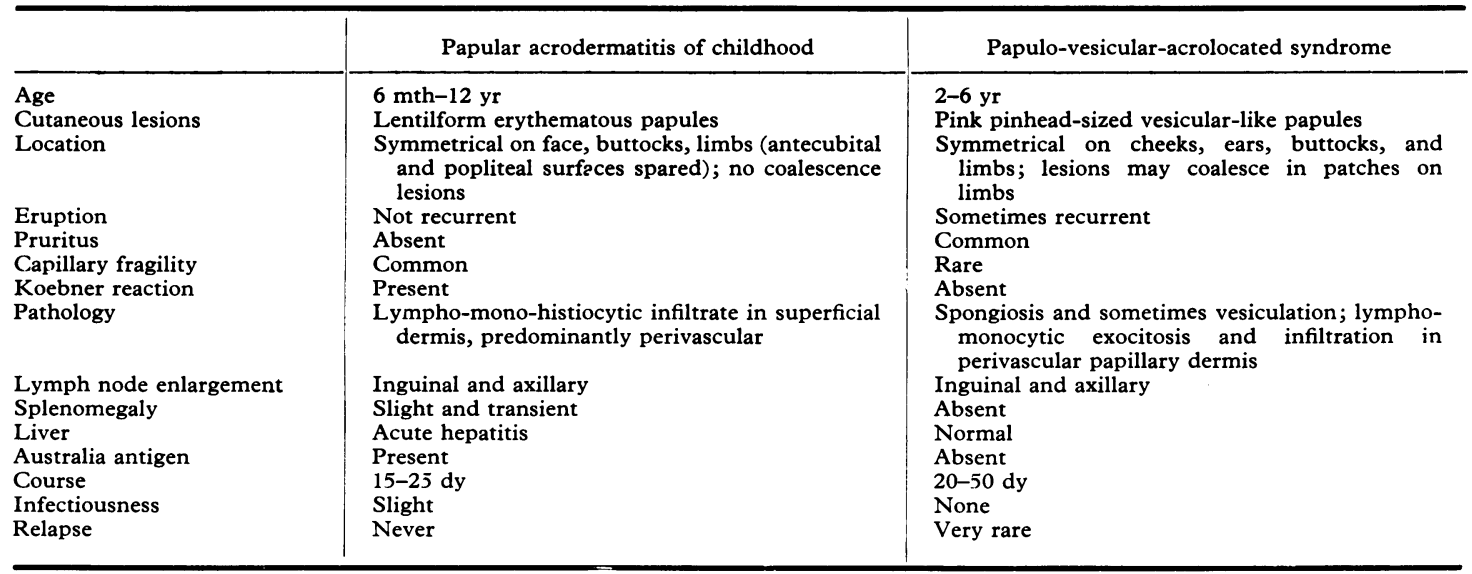

eruption and lymphadenitis, the lack of $\mathrm{Au}$ antigenaemia in the earliest phase, its occurrence without contact with human blood-might suggest that PAC and serum hepatitis are two different diseases due to different viruses. However, the fact that both are constantly associated with $\mathrm{Au}$ antigenaemia, and have similar microscopical and ultramicroscopical pathology, and that their contagiousness is low, suggests that the two conditions may be linked. If the two diseases are due to a single infectious agent, then PAC would represent the naturally occurring form of primary infection of the serum hepatitis disease. In keeping with this view, the primary infection of PAC occurs almost exclusively in children who are intially $\mathrm{AuAg}$ negative. If this view is correct, it is not clear why cases of serum hepatitis from inoculation of blood carrying $\mathrm{Au}$ are not associat $2 \mathrm{~d}$ with the cutaneous and lymph node manifestations of PAC. Possibly these manifestations appear only when the infection is acquired by cutaneous or mucous membrane routes, or when some particular genetic or immunological situation exists, as in the apparently high incidence of PAC in children with Down's syndrome.

\section{REFERENCES}

Bedarida, G., Trinchieri, G., and Carbonara, A. (1969). The detection cf Australia antigen and anti-Au antibodies by a rapid procedure combining electrophoresis and immunoprecipitation. Haematologica, 54, 591.

Bernhardt, E., and Szczepanski, A. (1968). Zespol GianottiegoCrostiego. Przeglad Dermatologiczny, 55, 513.

Blagoslovenskii, G. S. (1970). The Gianotti-Crosti syndrome in children. Voprosȳ Okhranȳ Materinstvai Detstva, 15, 84

Blancher, G., Sugier, J., Pringuet, G., Bach, C., and Rossier, A. (1962). Acrodermatite erythémato-papuleuse infantile (syndrome de Gianotti-Crosti). Contribution à la discussion de l'étiologie. Annales de Pédiatrie, 9, 609.
Bologa, E. I. (1966). Sur la participation hépatique dans l'acrodermatite papuleuse infantile. Syndrome de Gianotti-Crosti. Giornale Italiano di Dermatologia, 107, 1385.

Boyanov, L., Boyanov, B, and Dimitrova, I (1963). The clinical picture and pathogenesis of the Gianotti-Crosti syndrome. Vestnik Dermatologii $i$ Venerologit, 37, No. 2, 14.

Braun-Falco, O., and Rupec, M. (1964). Über das GianottiCrosti-Syndrom. Medizinische Klinik, 59, 210.

Brown, J., and Rentiers, P. (1969). The Gianotti-Crosti syndrome: a distinctive exanthem. Canadian Medical Association fournal, 100, 773.

Brunner, M. J., Rubin, L., and Dunlap, F. (1962). A new papular erythema of childhood. Archives of Dermatology, 85, 539.

Cieri, E., Rezza, E., and Anibaldi, A. (1966). Studio clinico di 8 casi di dermatite maculo-papulosa acroposta. Rivista di Clinica Pediatrica, 78, 361.

Costantino, D., Doglia, M., Bardare, M., and De Gaspari, G. (1973). Acrodermatite papulcsa infantile e antigeni associati all'epatite virale. Minerva Medica. (In the press.)

Crosti, A., and Gianotti, F. (1964). Ulteriore contributo alla conoscenza dell'acrodermatite papulosa infantile. Giornale Italiano de Dermatologia, 105, 477.

Dane, D. S., Cameron, C. H., and Briggs, M. (1970). Virus-like particles in serum of patients with Australia-antigen-associated hepatitis. Lancet, 1, 695.

De Benedetti, L. (1969). Un caso di ejatite anitterica con acrodermatite papulosa di Crosti Gianotti. Minerva Pediatrica, 21, 1401.

De Gaspari, G., Bardare, M., and Costantino, D. (1970). Au antigen in Crosti-Gianotti acrodermatitis. Lancet, 1, 1116.

De Groote, J., Desmet, V. J., Gedigk, P., Korb, G., Popper, H., Poulsen, H., Scheuer, P. J., Schmid, M., Thaler, H., Uehlinger, E., and Welper, W. (1968). A classification of chronic hepatitis. Lancet, 2, 626.

Despres, P., Pringuet, R., and Larrègue, M., Basset, Mme., Watchi, J. M., and Seringe, P. (1969). Syndrome de Gianotti-Crosti : à propos d'un cas, contribution à l'étude étiopathogénique. Annales de Pédiatrie, 16, 735.

Duperrat, B., and Puissant, A. (1958). La dermatite éruptive des extrémités chez les enfants (syndrome de Gianotti-Crosti). Presse Médicale, 66, 1862.

Eiloart, M. (1966). The Gianotti-Crosti syndrome. Report of forty-four cases. British fournal of Dermatology, 78, 488.

Gianotti, F. (1955). Rilievi di una particolare casistica tossinfettiva caratterizzata da una eruzione eritemato-infiltrativa desquamativa a focolai lenticolari, a sede elettiva acroesposta. Giornale Italiano di Dermatologia, 96, 678.

Gianotti, F. (1966). L'epatite anitterica virale nell'acrodermatite papulosa infantile. Epatologia, 12, 171. 
Gianotti, F. (1970). The Australia antigen in infantile papular acrodermatitis. Proceedings of the 6th Meeting of the European Association for the Study of the Liver, 2-4 September, London, Communication 16.

Gianotti, F. (1971). El antigeno Australia en la acrodermatitis papulosa infantil. Actas Dermo-sifiliográficas, 62, 227.

Hjorth, N., Kopp, H., and Osmundsen, P. E. (1967). GianottiCrosti syndrome; papular eruption of infancy. Transactions of the St. Fohn's Hospital Dermatological Society, 53, 46.

Jean, G., Lambertenghi, G., and Gianotti, F. (1968). Ultrastructural aspects of lymph-nodes in infantile papular acrodermatitis. Observation of virus-like particles. Dermatologica, 136, 350.

Jean, G., Lambertenghi, G., Gianotti, F., Travaglini, P., and Ranzi, T. (1967). L'Epatite Anitterica Nell'Acrodermatite Papulosa Infantile. Ganassini, Milano.

Jean, G., Ranzi, T., and Lambertenghi, G. (1969). Phagocytic activity of peripheral mononuclear blood cells in lymphoreticular disease. Ultrastructural study. Haematologica Latina, 12, 1.

Jenson, A. B., McCombs, R. M., Sakurada, N., and Melnick, J. L. (1970). Organ cultures inoculated with serum from a hepatitis patient with Au antigenemia. Experimental and Molecular Pathology, 13, 217.

Jeune, M., Moulin, G., and Rosenberg, D. (1964). A propos d'un cas d'acrodermatite papuleuse infantile. Pédiatrie, 19, 987.

Nurse, D. S. (1967). Infantile lichenoid acrodermatitis. Medical Fournal of Australia, 2, 1195.

Piřol-Aguade, J., and Mascaro, J. M. (1971). Dos casos de sindrome de Gianotti-Crosti con antígeno Australia positivo. Actas Dermo-sifiliográficas, 62, 95.

Pomposiello, I. M., and Abulafia, J. (1968). Gianotti-Crosti syndrome. Archivos Argentinos de Dermatologia, 18, 113.

Prince, A. M. (1968). Au antigen detected in the blood during an incubation period of serum hepatitis. Proceedings of the National Academy of Sciences of the U.S.A., 60, 814.

Puissant, A., Mascaro, J. M., Fauchier, A., and Canet, J. (1966). Syndrome éruptif érythémato-vésiculo-papuleux simple localisé aux extrémités de Gianotti-Crosti. Annales de Dermatologie et de Syphiligraphie, 93, 279.
Reich, H. (1963). Das Gianotti-Crosti Syndrom. Hautarzt, 14, 315.

Ricciardiello, P. T. (1969). Acrodermatite papulosa infantile accompagnata da epatite ed ittero. Giornale di Malattie Infettive e Parassitarie, 21, 213.

Schirren, C. G., and Mütter, M. (1964). Die Akrodermatitis papulosa infantum (Gianotti-Crosti Syndrom) im differentialdiagnostischen Grenzgebiet von Dermatologie und Pädiatrie. Monatsschrift für Kinderheilkunde, 112, 65.

Sirtori, C. (1970). Virus-like particles in infectious hepatitis. Lancet, 2, 824.

Stein, O., Fainaru, M., and Stein, Y. (1972). Visualization of virus-like particles in endoplasmic reticulum of hepatocytes of Australia antigen carriers. Laboratory Investigation, 26, 262.

Stevanovic, D. V., and Sofronic, A. D. (1962). Gianotti-Crosti syndrome (subacute infective reticulo-endothelitis). Transactions of the St. Fohn's Hospital Dermatological Society, 48, 83.

Terao, T., and Takemura, T. (1971). Le syndrome de GianottiCrosti au Japon. Bulletin de la Société Française de Dermatologie et de Syphiligraphie, 78, 116.

Thiers, H., and Moulin, G. (1964). L'acrodermatite érythématopapuleuse infantile (syndrome de Gianotti-Crosti). A propos de deux observations. Fournal de Médecine de Lyon, 45, 2173.

Vulcan, P. Wolkonsky, A., and Nicolescu, F. (1965). Acrodermatita eritemapapuloasa infantila (sindromul GianottiCrosti). Consideratii privind doua cazuri clinice. DermatoVenerologia, 10, 309.

Waisman, M., and Sutton, R. L. (1966). Frictional lichenoid eruption in children. Archives of Dermatology, 94, 592.

Winkelmann, R. K., and Bourlond, A. (1965). Infantile lichenoid acrodermatitis. Report of a case of Gianotti-Crosti syndrome. Archives of Dermatology, 92, 398.

Woerdeman, M. J. (1965). Acrodermatitis papulosa infantilis. Syndroom van Gianotti-Crosti. Nederlands Tijdschrift voor Geneeskunde, 109, 1472.

Correspondence to Professor F. Gianotti, Clinica Dermatologica, Universita di Milano, Via Pace 9, 20122 Milano, Italy. 